\title{
Single Incision Percutaneous Pedicle Screw Fixation for Transforaminal Lumbar Interbody Fusion
}

\author{
Sung Hoon Han ${ }^{1}$, Suk-Hyung Kang ${ }^{2}$, Yong-Jun Cho ${ }^{2}$, Tack Geun Cho ${ }^{1}$ \\ ${ }^{I}$ Department of Neurosurgery, Kangnam Sacred Heart Hospital, Hallym University College of Medicine, Seoul, \\ ${ }^{2}$ Department of Neurosurgery, Chuncheon Sacred Heart Hospital, Hallym University College of Medicine, Chuncheon, Korea
}

Objective: Percutaneous pedicle screw fixation (PPSF) offers some of the advantages of minimally invasive surgery. However, an additional skin incision is necessary in order to gain these advantages. The author recently performed a modified PPSF through a single skin incision and it yielded good results. Here, we report the single incision percutaneous pedicle screw fixation (SIPPSF).

Methods: The medical records of 51 patients who underwent single segment transforaminal lumbar interbody fusion (TLIF) with pedicle screw fixation (PSF) between December 2009 and December 2011 were reviewed. The patients were divided into 3 groups according to the PSF technique used; conventional group (Group C), SIPPSF (Group S) and PPSF through multiple skin incisions (Group M). Operation time, estimated blood loss (EBL) and pain intensity before and after the operation using a numeric rating scale (NRS) were evaluated.

Results: The number of patients in Group S, Group C and Group M was 25, 17 and 9, respectively. The NRS demonstrated a reduction in pain intensity in all the patients, and there were no differences in NRS scoring between the three groups. Group $S$ showed a reduction in the EBL compared to Group $C(p=0.001)$ and a reduction in the operation time compared to Group M ( $\mathrm{p}=0.003)$.

Conclusion: The author supposes that the type of skin incision does not correlate significantly with the clinical results of TLIF with PPSF. However, it can be considered that SIPPSF offers the advantage of avoiding an additional paramedian skin incision.

Key Words: Percutaneous pedicle screw $\cdot$ Minimally invasive $\cdot$ Transforaminal lumbar interbody fusion

\section{INTRODUCTION}

Transforaminal lumbar interbody fusion (TLIF) has been recognized as an effective method for treating degenerative lumbar spinal stenosis ${ }^{4}$. TLIF is usually used together with pedicle screw fixation (PSF) in spinal surgery. PSF has been widely recognized as an effective method for treating spinal instability ${ }^{3,5}$. However, conventional PSF requires extensive tissue dissection and excessive traction of paravertebral mus-

\footnotetext{
- Received: April 30, 2012 - Revised: June 22, 2012

- Accepted: June 25, 2012

Corresponding author: Suk-Hyung Kang, MD

Department of Neurosurgery, Chuncheon Sacred Heart Hospital, 153

Gyo-dong, Chuncheon-si, 200-704 Korea

Tel : +82-33-240-5173, Fax : +82-33-242-9970

E-mail: nscharisma@hanmail.net

"There is nothing to disclosure, financially.
}

cles in order to secure the trace and entry point of pedicle screws, which results in weakness of vertebral supporting structures in addition to other problems such as significant blood loss ${ }^{13)}$. In order to solve these problems, percutaneous pedicle screw fixation (PPSF) was introduced as a minimal invasion meth$\mathrm{od}^{16)}$.

Percutaneous pedicle screw fixation (PPSF) is an advanced method of PSF maintaining merits. PPSF is advantageous in terms of operative time and blood loss, and protects midline structure of the spine with reduced muscle dissection $1^{7,9,15}$, $17,18,20,23,24)$. However, an additional skin incision is necessary in order to gain these advantages. In order to overcome this limitation, we invented a method of using single skin incision. This method was compared with conventional PSF with TLIF and multiple skin incision PPSF in terms of operative time, blood loss and pain intensity before and after the operation are described in the present study. 


\section{MATERIAL AND METHODS}

\section{Materials}

A total of 51 patients who underwent TLIF on a single segment at two hospitals between December 2009 and December 2011 were selected, and medical records were retrospectively investigated for the present study. Surgical indications of TLIF with PSF included cases of symptomatic herniated lumbar disc with segmental instability, lumbar stenosis, and spondylolisthesis or segmental instability of the lumbar spine. The patients were divided into 3 groups according to the PSF technique used; conventional PSF with TLIF (Group C), single incision PPSF (Group S) and PPSF through multiple skin incisions (Group M). Patients who underwent surgery with other indications including fracture, tumor or infection were excluded from the present study. In all subjects, Operation time, estimated blood loss (EBL) and pain intensity before and after the operation using a numeric rating scale (NRS) were evaluated for assessment. Postsurgical NRS was checked before discharge. Followup NRS was not involved in this study. Surgeries were performed by 4 specialists: Group C and Group $\mathrm{S}$ by senior surgeons, and Group $\mathrm{M}$ by a junior surgeon with less than 10 years experiences.

\section{Methods of operation}

Conventional PSF method of Group C includes steps of performing: subperiosteal dissection at the both sides of midline structure to expose both facet joints and transverse processes; TLIF; and traction of paravertebral muscles to expose the site for insertion of pedicle screws.

Method of TLIF and single incision percutaneous pedicle screw fixation (SIPPSF) for Group S includes steps of: general anesthesia; drawing lines parallel to endplate of relevant vertebra at each pedicle site based on the center of surgical site vertebra using $\mathrm{C}$-arm at prone position; making a midline skin incision 2 times longer than the parallel line by extending half of the length between parallel lines up and down; accessing to the affected side to dissect fascia layer in an appropriate size to perform TLIF; performing additional surgery if decompression is necessary at the opposite side; inserting a drain tube and suturing fascia layer; securing a space for inserting pedicle screws between thoracolumbar fascia and subcutaneous fat tissues without additional skin incision; inserting a guide needle to relevant pedicle under C-arm guide; performing PPSF (GS medical AnyPlus OR MIS system GSSTM) and fixation (Fig. 1); and performing the same procedure at the

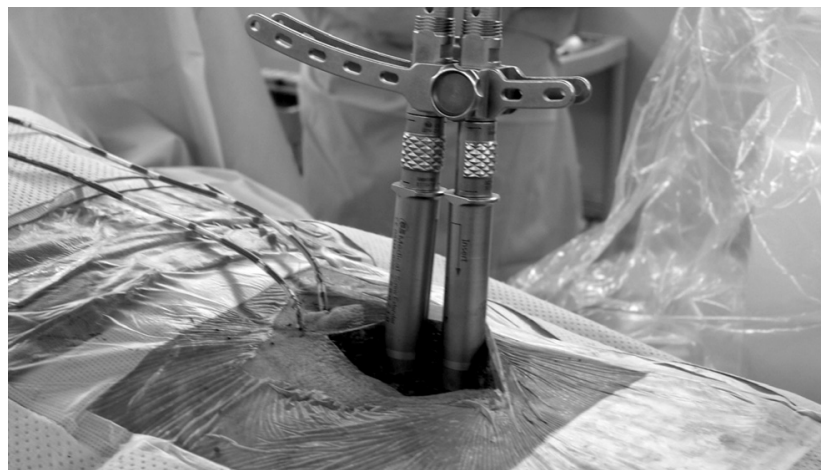

Fig. 1. Intraoperative photograph of single incision percutaneous pedicle screw fixation.

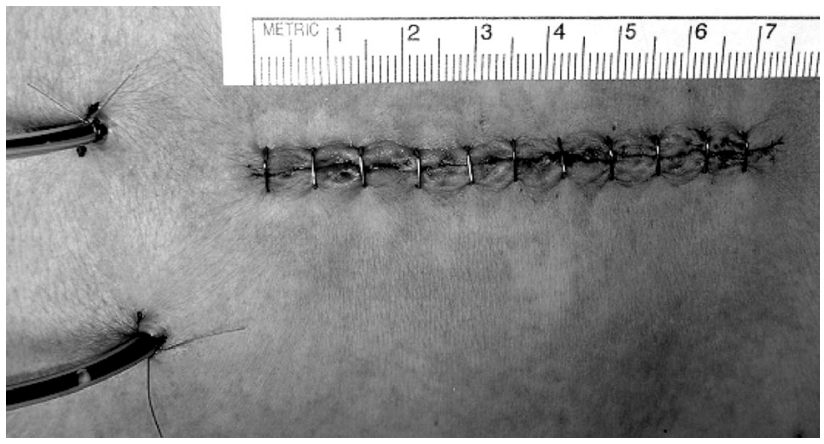

Fig. 2. Postoperative scar of single incision percutaneous pedicle screw fixation.

other side before irrigation and suturing the wound (Fig. 2).

Method of multiple skin incision PPSF (Medtronic CD HORIZONO ${ }^{(}$SEXTANT $^{\mathrm{TM}}$ ) for Group M is similar to that of SIPPSF performing TLIF through midline skin incision. After then, 4 more small skin incisions are made after confirming insertion sites for pedicle screws using C-arm before inserting screws. Finally, additional 2 small incisions are made for rod insertion, and rods are inserted.

\section{Statistical analysis}

Student's t-test was conducted on the collected data. Firstly, T-test was conducted to investigate operative time, EBL and perioperative difference in NRS in Group S and Group C. Secondly, T-test was conducted in Group $S$ and Group $M$ to investigate the same items. Significance of data was assumed with the p-value at 0.05 or less.

\section{RESULTS}

The 51 patients who underwent TLIF at the 2 hospitals between December 2009 and December 2011 included 25 in 
Group S, 17 in Group C and 9 in Group M. Mean age of Group $S$ was $60.8 \pm 9.6$ (43-82), group C $54.4 \pm 13.9$ (21-72), and Group M 63.7 \pm 7.6 (51-79). Male/female ratio was $10 / 15$ in Group S, 10/7 in Group C, and 5/4 in Group M. Regarding preoperative diagnosis, instability including spondylolisthesis most common with 21 cases (41.2\%). In terms of fusion level, L4-5 level was most common with 38 cases (74.5\%). Additionally, frequency analysis was conducted on the factors such as age, gender, preoperative diagnosis and surgical site, but no significant difference was observed among groups (Table 1).
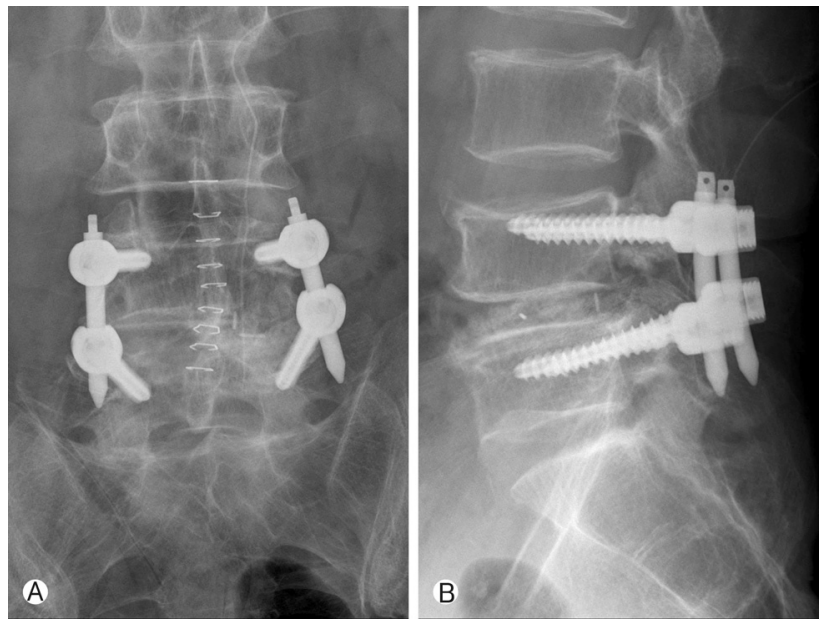

Fig. 3. Postoperative X-ray finding. (A) Anteroposterior radiographic image. (B) Lateral radiographic image.
In terms of operative time and EBL, Group S showed 182.8 \pm 40.1 minutes (125-290 minutes) and $316 \pm 146.3 \mathrm{~mL}(100$ $600 \mathrm{~mL}$ ), respectively. The overall NRS of the whole patients improved from preoperative $7.4 \pm 1.3$ to postoperative $1.0 \pm$ 0.8 , respectively. When Group S and Group C were compared, no statistical difference in operative time and changes in perioperative NRS was observed, but EBL were $316.0 \pm 146.3 \mathrm{~mL}$ and $526.5 \pm 219.5 \mathrm{~mL}$ showing significantly less EBL in Group $S$ than Group C $(\mathrm{p}=0.001)$ (Table 2).

When Group $S$ and Group $M$ were compared, EBL and perioperative change in NRS did not show statistically significant difference, but operative time showed $182 \pm 40.1$ minutes and $231.7 \pm 39.0$ minutes, respectively meaning a significantly short period in Group S compared with Group $\mathrm{M}(\mathrm{p}=0.003)$ (Table 3).

When Group C and Group M were compared, EBL and perioperative change in NRS did not show statistically significant difference, but operative time showed 194.7 \pm 38.7 minutes and $231.7 \pm 39.0$ minutes, respectively meaning a significantly short period in Group C compared with Group M $(\mathrm{p}=0.003)$ (Table 4).

In all patients, no complication such as surgical site infection, fracture and neurologic damage associated with surgery was observed during hospital stay.

\section{DISCUSSION}

TLF is gaining a popularity these days because nerve decom-

Table 1. Patient information

\begin{tabular}{llllll}
\hline \hline & Group S & Group C & Group M & Total & p-value \\
\hline No. of patients & 25 & 17 & 9 & 51 & \\
Age (years) & $60.8 \pm 9.6$ & $54.4 \pm 13.9$ & $63.7 \pm 7.6$ & $59.2 \pm 11.3$ & $0.078^{*}$ \\
Gender (M/F) & $10 / 15$ & $10 / 7$ & $5 / 4$ & $25 / 26$ & $0.445^{+}$ \\
Index diagnosis (no. of patients) & & & & & $0.229^{+}$ \\
$\quad$ Spinal stenosis & 8 & 5 & 3 & $16(31.4 \%)$ & \\
$\quad$ HNP & 5 & 4 & 5 & $14(27.5 \%)$ & \\
Instability including spondylolisthesis & 12 & 8 & 1 & $21(41.2 \%)$ & \\
Level of fusion (no. of patients) & & & & & $0.346^{+}$ \\
L1-2 & 1 & 0 & 0 & $1(2.0 \%)$ & \\
L2-3 & 0 & 3 & 0 & $3(5.9 \%)$ & \\
L3-4 & 2 & 2 & 0 & $4(7.8 \%)$ & \\
L4-5 & 19 & 11 & 8 & $38(74.5 \%)$ & \\
L5-S1 & 3 & 1 & 1 & $5(9.8 \%)$ & \\
\hline
\end{tabular}

Group S means Single Incision Percutaneous Pedicle Screw Fixation (SIPPSF) group.

Group $C$ means Conventional pedicle screw fixation group.

Group $M$ means Multiple skin incision percutaneous pedicle screw fixation group.

*Result of Analysis of Variance (ANOVA).

${ }^{+}$Results of Pearson's Chi square. 
Table 2. Comparison of surgical results between single Incision percutaneous pedicle screw fixation (SIPPSF, group S) and conventional pedicle screw fixation (group C)

\begin{tabular}{lccc}
\hline \hline & Group S & Group C & p-value \\
\hline Operation time $(\mathrm{min})$ & $182.8 \pm 40.1$ & $194.7 \pm 38.7$ & 0.344 \\
Estimated blood loss $(\mathrm{mL})$ & $316.0 \pm 146.3$ & $526.5 \pm 219.5$ & 0.001 \\
Preoperative NRS & $7.6 \pm 1.0$ & $7.6 \pm 1.0$ & 0.071 \\
Postoperative NRS & $1.2 \pm 0.8$ & $0.7 \pm 0.7$ & 0.063 \\
\hline
\end{tabular}

Table 3. Comparison of surgical results between single Incision percutaneous pedicle screw fixation (SIPPSF, group S) and multiple incisions percutaneous pedicle screw fixation (group M)

\begin{tabular}{lccc}
\hline \hline & Group S & Group M & p-value \\
\hline Operation time $(\mathrm{min})$ & $182.8 \pm 40.1$ & $231.7 \pm 39.0$ & 0.003 \\
Estimated blood loss $(\mathrm{mL})$ & $316.0 \pm 146.3$ & $422.2 \pm 146.0$ & 0.071 \\
Preoperative NRS & $7.6 \pm 1.0$ & $7.4 \pm 1.2$ & 0.647 \\
Postoperative NRS & $1.2 \pm 0.8$ & $1.3 \pm 0.9$ & 0.589 \\
\hline
\end{tabular}

Table 4. Comparison of surgical results between conventional pedicle screw fixation (group C) and Multiple incisions percutaneous pedicle screw fixation (group M)

\begin{tabular}{lccc}
\hline \hline & Group C & Group M & p-value \\
\hline Operation time $(\mathrm{min})$ & $194.7 \pm 38.7$ & $231.7 \pm 39.0$ & 0.030 \\
Estimated blood loss $(\mathrm{mL})$ & $526.5 \pm 219.5$ & $422.2 \pm 146.0$ & 0.214 \\
Preoperative NRS & $7.6 \pm 1.0$ & $7.4 \pm 1.2$ & 0.372 \\
Postoperative NRS & $0.7 \pm 0.7$ & $1.3 \pm 0.9$ & 0.054 \\
\hline
\end{tabular}

pression and cage insertion are possible through even a unilateral exposure ${ }^{4)}$. In addition, disc space can be exposed and the central structure can be preserved with reduced nerve traction. However, like other open posterior approaches, dissection and traction of paravertebral muscles are required, and consequent problems are reported ${ }^{10)}$. Moreover, PSF should be simultaneously performed in order to enhance spinal stability and prevent mobility of the inserted cage ${ }^{5)}$. However these conventional PSF requires an extensive skin incision to secure a entry point and sufficient cortical bone surface. Accordingly, the damage of the paravertebral supporting structures is unavoi dable, and additional problems such as surgical site infection, increased blood transfusion due to copious bleeding, extended hospital stay and increased medical expenses of patients have been reported in the precedent studies ${ }^{1,9,11,14,15,17,19,24)}$.

Excessive dissection and traction of paravertebral muscle tissues during surgery can induce muscular atrophy and consequently, risk of developing postoperative lumbar pain increases $^{6,8,21)}$.

Kawaguchi et al..$^{8)}$ determined that back muscle injury, in terms of elevated serum levels of creatine phosphokinase MM isoenzyme which is an index of muscle damage, is directly related to the retraction pressure, time, and extent of exposure.
Gejo et al. ${ }^{6}$ concluded that an increase in T2 signal intensity on serial MRIs is correlated with longer muscle retraction time during surgery. In addition, they reported a significant increase in postoperative lumbar pain in the patients who had muscle traction for long time. Rantanen et al. ${ }^{21)}$ reported consistent pathological changes in paravertebral muscles in case of the patients who have poor postoperative lumbar results. In order to supplement these problems, minimally invasive posterior lumbar fixation through PPSF has been developed ${ }^{1,7,15,23,24)}$.

As a result of performing PPSF, extensive skin incision and damage in paravertebral supporting structures which were made during the conventional spinal fixation procedure were minimized, and development of complications such as copious bleeding and risk of infection reduced. In addition, postoperative joint damage and pain caused by atrophy in paravertebral muscles also decreased ${ }^{1,7,9,11,12,15,17,18,20,23,24)}$. However, additional skin incision is necessary for PPSF. Various devices to supplement this limitation have been developed, but utility of the devices has not been proved yet. Additionally, various complications associated with PPSF have been reported. Schwender et al. ${ }^{22)}$ reported surgical complications such as malposition of pedicle screws, cage displacement and iatrogenic foraminal stenosis developed in about $6.1 \%$ of the total cases 
performed PPSF using the sextant system. Dhall et al. ${ }^{2)}$ reported cases of surgical complications such as abnormal pedicle screws site, cage displacement and dural laceration in 14.2\% of the total cases. In many studies, necessity of accurate interpretation of fluoroscopic images and learning curve was reported in order to use the sextant system which has a different surgical method from conventional PSF.

In the present study, we invented a new surgical method, and applied it in order to minimize problems of the conventional methods, and to maintain merits of PPSF at the same time and compare the results. As a result, SIPPSF did not show a statistical significance in operative time and change in perioperative pain level compared with conventional PSF, but has an evident advantage in bleeding amount during surgery. In addition, compared with multiple skin incision PSF, SIPPSF showed a slight decrease in bleeding amount but the difference did not reach statistical significance. Instead, SIPPSF had significance in reduction in operative time, even though number of comparing patient group was only. Other reasons on this result may include difference in skill of surgeons. Even though difference in operative time caused by difference in experience among surgeons who performed SIPPSF, conventional PSF and multiple skin incision PPSF was observed, no difference was reported in NRS showing indirect results of surgery. In addition, difference in EBL with group $\mathrm{C}$ indicates a minimal invasiveness of SIPPSF.

Interesting finding of this study was Group M results. Group C showed shorter operation time than Group M. $(p=0.030)$ However, in the EBL, it did not show any difference with Group C. Group M of this study represented young surgeon. The number of Group $\mathrm{M}$ was 9 and it is smaller than other group. We think these factors may be associated with the results of Group M.

In the present study, NRS indicating patient satisfaction and prognosis decreased in both conventional surgery patient group and percutaneous surgery patient group, but difference between the groups did not reach statistical significance. By comparison, some studies reported that reduction in visual analogue scale in minimal invasion surgery group was more than that in conventional surgery group $1^{3,9,15,17,18,20,23,24)}$.

\section{CONCLUSION}

When TLIF with PPSF are performed, skin incision does not affect results of surgery. The proposed procedure, single incision PPSF (SIPPSF), in the present study supposed to have the merits of PPSF which can obtain medial angle without additional muscle dissection and preserve mid-line structures.

\section{REFERENCES}

1. Adogwa O, Parker SL, Bydon A, Cheng J, McGirt MJ: Comparative effectiveness of minimally invasive versus open transforaminal lumbar interbody fusion: 2-year assessment of narcotic use, return to work, disability, and quality of life. J Spinal Disord Tech 24:479-484, 2011

2. Dhall SS, Wang MY, Mummaneni PV: Clinical and radiographic comparison of mini-open transforaminal lumbar interbody fusion with open transforaminal lumbar interbody fusion in 42 patients with long-term follow-up. J Neurosurg Spine 9:560-565, 2008

3. Fang LM, Zhang YJ, Zhang J, Huang N, Lin HG, Li B, et al: Treatment of lumbar disc herniation by modified transforaminal lumbar interbody fusion with a pedicle screw system. Zhonghua Yi Xue Za Zhi 90:3339-3342, 2010

4. Foley KT, Holly LT, Schwender JD: Minimally invasive lumbar fusion. Spine (Phila Pa 1976) 28:S26-35, 2003

5. Gaines RW, Jr.: The use of pedicle-screw internal fixation for the operative treatment of spinal disorders. J Bone Joint Surg Am 82-A:1458-1476, 2000

6. Gejo R, Kawaguchi Y, Kondoh T, Tabuchi E, Matsui H, Torii $\mathrm{K}$, et al: Magnetic resonance imaging and histologic evidence of postoperative back muscle injury in rats. Spine (Phila Pa 1976) 25:941-946, 2000

7. Karikari IO, Isaacs RE: Minimally invasive transforaminal lumbar interbody fusion: a review of techniques and outcomes. Spine (Phila Pa 1976) 35:S294-301, 2010

8. Kawaguchi Y, Matsui H, Tsuji H: Changes in serum creatine phosphokinase MM isoenzyme after lumbar spine surgery. Spine (Phila Pa 1976) 22:1018-1023, 1997

9. Kotani Y, Abumi K, Ito M, Sudo H, Abe Y, Minami A: Midterm clinical results of minimally invasive decompression and posterolateral fusion with percutaneous pedicle screws versus conventional approach for degenerative spondylolisthesis with spinal stenosis. Eur Spine J 21:1171-1117, 2011

10. Lau D, Lee JG, Han SJ, Lu DC, Chou D: Complications and perioperative factors associated with learning the technique of minimally invasive transforaminal lumbar interbody fusion (TLIF). J Clin Neurosci 18:624-627, 2011

11. Lee P, Fessler RG: Perioperative and postoperative complications of single-level minimally invasive transforaminal lumbar interbody fusion in elderly adults. J Clin Neurosci 19:111-114, 2012

12. Lim TK, Lee SG, Park CW, Kim WK: Comparative analysis of clinical outcomes and adjacent level angle change on singlelevel lumbar 4-5 fusion using percutaneous screw fixation and open screw fixation. Korean J Spine 7(4):228-233, 2010

13. Lu C, Lu GH, Ma ZM: [Analysis of complication in the spinal pedicle screw internal fixation]. Hunan Yi Ke Da Xue Xue Bao 25:51-52, 2000

14. McGirt MJ, Parker SL, Lerner J, Engelhart L, Knight T, Wang MY: Comparative analysis of perioperative surgical site infe- 
ction after minimally invasive versus open posterior/transforaminal lumbar interbody fusion: analysis of hospital billing and discharge data from 5,170 patients. J Neurosurg Spine 14:771778, 2011

15. Ntoukas V, Muller A: Minimally invasive approach versus traditional open approach for one level posterior lumbar interbody fusion. Minim Invasive Neurosurg 53:21-24, 2010

16. Oppenheimer JH, DeCastro I, McDonnell DE: Minimally invasive spine technology and minimally invasive spine surgery: a historical review. Neurosurg Focus 27:E9, 2009

17. Park Y, Ha JW: Comparison of one-level posterior lumbar interbody fusion performed with a minimally invasive approach or a traditional open approach. Spine (Phila Pa 1976) 32: 537-543, 2007

18. Park Y, Ha JW, Lee YT, Oh HC, Yoo JH, Kim HB: Surgical outcomes of minimally invasive transforaminal lumbar interbody fusion for the treatment of spondylolisthesis and degenerative segmental instability. Asian Spine J 5:228-236, 2011

19. Parker SL, Adogwa O, Bydon A, Cheng J, McGirt MJ: CostEffectiveness of Minimally Invasive versus Open Transforaminal Lumbar Interbody Fusion for Degenerative Spondylolisthe- sis Associated Low-Back and Leg Pain Over Two Years. World Neurosurg 7, 2011

20. Payer M: "Minimally invasive" lumbar spine surgery: a critical review. Acta Neurochir (Wien) 153:1455-1459, 2011

21. Rantanen J, Hurme M, Falck B, Alaranta H, Nykvist F, Lehto $\mathrm{M}$, et al.: The lumbar multifidus muscle five years after surgery for a lumbar intervertebral disc herniation. Spine (Phila Pa 1976) 18:568-574, 1993

22. Schwender JD, Holly LT, Rouben DP, Foley KT: Minimally invasive transforaminal lumbar interbody fusion (TLIF): technical feasibility and initial results. J Spinal Disord Tech 18 Suppl:S1-6, 2005

23. Shunwu F, Xing Z, Fengdong Z, Xiangqian F: Minimally invasive transforaminal lumbar interbody fusion for the treatment of degenerative lumbar diseases. Spine (Phila $\mathrm{Pa} \mathrm{1976)} \mathrm{35:}$ 1615-1620, 2010

24. Wang J, Zhou Y, Zhang ZF, Li CQ, Zheng WJ, Liu J: Minimally invasive or open transforaminal lumbar interbody fusion as revision surgery for patients previously treated by open discectomy and decompression of the lumbar spine. Eur Spine J 20: 623-628, 2011 